\title{
Should I prescribe sunlight instead of vitamin D?
}

\author{
Diane Kelsall MD MEd
}

See also review article by Papaioannou and colleagues at www.cmaj.ca

$\mathrm{W}$ ith the increased understanding of the effects of vitamin $\mathrm{D}$ on the body and the growing evidence that people living in northern climes have inadequate levels of vitamin D during the winter months, I wondered whether I should be prescribing sunlight for my patients. After all, a mild sunburn after 5 to 10 minutes of sun exposure in the peak of summer can synthesize as much as 20000 IU of vitamin $\mathrm{D}^{1}-20$ days' worth of the often recommended 1000 IU vitamin D supplement taken daily. ${ }^{2}$

We all know that a sunburn is not good for your skin, but what about a more modest tan? If I were to go out for four minutes at lunchtime on a sunny day in July wearing shorts and a T-shirt, my body would generate about $1000 \mathrm{IU}$ of vitamin D (I am fair with freckles). ${ }^{3.4}$ That seems reasonable, doesn't it? A person with darker skin colour would need to enjoy some additional time in the sun to achieve the same result, but I suspect that my patients would be very happy to receive such a prescription and that adherence to my advice would be quite high.

According to the American Academy of Dermatology and the Canadian Dermatology Association position statements on vitamin $\mathrm{D},{ }^{5,6}$ however, I would be doing my patients a serious disservice. These groups are clear that there is no scientifically validated, safe threshold level for ultraviolet exposure from the sun (or indoor tanning devices) that allows for appropriate vitamin D synthesis without increasing the risk of skin cancer. Encouraging patients to increase their exposure to the sun is a bad idea. Instead, the groups recommend that physicians discuss the use of oral vitamin D supplements, particularly for the winter months, with their patients.

Deputy Editor, Clinical Practice, CMAJ

CMAJ 2010. DOI:10.1503/cmaj.100282
Not everyone agrees with the dermatologists; instead some decry the demonization of sunlight and argue that people are unlikely to take vitamin supplements ad infinitum. But I'm siding with the dermatologists on this one. In short, the answer is no to prescribing sunlight for my patients. Instead, oral vitamin D supplements and sunblock are healthier topics for discussion. Now I just have to figure out a way to persuade my patients to take their vitamins.

This article has been peer reviewed.

Competing interests: None declared.

Diane Kelsall is Deputy Editor, Clinical Practice for CMAJ and was not involved in the editorial decision-making process for this article.

\section{REFERENCES}

1. Hollis BW. Circulating 25-hydroxyvitamin D levels indicative of vitamin D sufficiency: implications for establishing a new effective dietary intake recommendation for vitamin D. J Nutr 2005; 135:317-22.

2. Hanley DA, Cranney A, Jones G, et al.; for the Guidelines Committee of the Scientific Advisory Council of Osteoporosis Canada. Vitamin D in adult health and disease: a review and guideline statement from Osteoporosis Canada (summary). CMAJ 2010;182:1315-9.

3. Webb AR. Who, what, where and when - influences on cutaneous vitamin D synthesis. Prog Biophys Mol Biol 2006;92:17-25.

4. Working Group of the Australian and New Zealand Bone and Mineral Society, Endocrine Society of Australia, Osteoporosis Australia. Vitamin D and adult bone health in Australia and New Zealand: a position statement. Med J Aust 2005;182: 281-5.

5. American Academy of Dermatology and the American Academy of Dermatology Association. Position statement on vitamin D. Schaumburg (United States of America): The Academies; 2009. Available: www.aad.org/forms/policies/uploads /ps/ps-vitamin\%20d.pdf (accessed 2010 Nov. 1).

6. Canadian Dermatology Association. Canadian Dermatology Association Position Statement: safe and effective way to maintain adequate levels of vitamin D. Ottawa (ON): The Association; 2009. Available: www.dermatology.ca/media /position_statement/vitamin_d.html (accessed 2010 Nov. 1).

Correspondence to: diane.kelsall@cmaj.ca 